\title{
Chemistry Provision for Primary Pupils: The Experiences of 10 Years of Bristol ChemLabS Outreach
}

\author{
Timothy G. Harrison", Dudley E. Shallcross \\ School of Chemistry, Cantock's Close, University of Bristol, UK
}

Copyright $\mathrm{C} 2016$ by authors, all rights reserved. Authors agree that this article remains permanently open access under the terms of the Creative Commons Attribution License 4.0 International License

\begin{abstract}
Bristol ChemLabS, the UK's Centre for Excellence in Teaching and Learning in practical chemistry, delivers numerous outreach activity days per year for thousands of primary school pupils annually. These mainly comprise demonstration assemblies and hands on workshops for pupils in the main. The activities support the UK's Key Stage 2 science curriculum, to raise scientific understanding among the teachers and to raise pupils' science skills and aspirations and are used by overseas universities to with the same advantage objective. The Bristol ChemLabS Outreach programme is self-financing. This paper highlights the advantages of the programme to the pupils, their teachers, the postgraduates that help deliver the workshops and to higher education institutes. The paper also provides a blueprint for anyone wishing to do such work.
\end{abstract}

Keywords Primary, Outreach, Sustainability

\section{Introduction}

Bristol ChemLabS is the project name for the UK's Centre for Excellence in Teaching and Learning (CETL) in practical chemistry based within the School of Chemistry, University of Bristol. As part of a Higher Education Funding Council for England (Hefce) funded project, launched in 2005, an outreach element was included to expand the existing School of Chemistry outreach programme in a sustainable way $[1,2]$. This was facilitated by funding to provide dedicated outreach equipment and to add a School Teacher Fellow (STF) [3, 4] to the academic staff to assist in the expansion of the outreach capacity of the department. A STF is a highly experienced secondary school chemistry teacher that is charged with using the resources of the department to promote chemistry regionally, nationally and internationally. Several UK chemistry departments have taken on a STF on a one year secondment and have retained them because of the myriad impacts they have had, including those on undergraduate and postgraduate students' teaching and learning [5].
In a statement by the director of the UK's Office of Fair Access (OFFA), universities were charged with providing outreach activities for primary school pupils, rather than just the traditional audience of senior secondary pupils, if the universities wish to maintain their ability to charge $£ 9000$ per year for courses [6].

Bristol ChemLabS Outreach engages with around 10000 primary school pupils (aged 4-11) per year through numerous events with the majority being demonstration assemblies and hands-on chemistry workshops [7-9]. During $2014 / 15$, there were 66 events organised for 10,912 primary pupils and teachers from 170 identified schools during the year. This paper will describe the main activities, the value to the pupils, the school teachers, the undergraduate and postgraduate students involved and how this aspect of the wider outreach portfolio is made sustainable.

\section{Main Primary Engagement Activities}

The practical demonstration presentation, which is normally given in place of an assembly, is entitled 'Gases in the Air'. The presentation is an hour long with numerous exciting demonstration experiments. This is not a 'magic show', each experiment is explained using ideas and language appropriate to primary school science level. The talk generally supports the Science curriculum (8-11 year olds) in that it investigates what is and is not a reversible change which encompasses changes of state and chemical reactions. The assembly demonstrates the combustion, or lack of it, of hydrogen and helium gases in filled balloons. Liquid nitrogen is used to explain many reversible properties such as state changes and expansion and contraction through a number of standard liquid nitrogen demonstrations using flowers, rubber tubing, rubber gloves, bananas, eggs and long inflated balloons. Chemical change is explained through the decomposition of hydrogen peroxide (the classic 'elephant's toothpaste' experiment) and the spectacular combustion of methanol vapour in a 20 litre water container (the 'whoosh bottle' experiment). Dry ice is used to demonstrate sublimation and to test the pupils' own observational skills. Here (observation skills), dry ice is 
added to an alkaline solution containing universal indicator, a demonstration that shows physical and chemical changes as the carbon dioxide dissolves and neutralizes the alkaline solution, bringing about indicator colour change. The assembly finishes with the destructive analysis of the low density gases in two balloons thus allowing the pupils to use their newly acquired chemical knowledge to identify gases. Typically the headteacher will test the last balloon which is always hydrogen as demonstration assemblies should finish with a bang and the pupils love seeing the shock on the face of their headteacher! The assembly is presented by the STF, a postdoctoral chemist employed part time to work in primary outreach or one of several trained postgraduate chemistry students. The assembly is delivered with considerable humour and with pace. These take place in the primary school hall with as many pupils in the audience as can both comfortably see the demonstrations and be far enough back for safety considerations. In very large schools up to 3 demonstration assemblies can take place in the morning. Importantly, the class teachers are also present. Often secondary schools provide the premises and invite in the senior students from their main feeder primary schools as a PR exercise. In such cases several science assemblies are performed per day, with occasionally, other science related activities provided by the hosts in other parts of the school complex.

\section{"It was amazing. I learnt a lot in your presentation. I learnt so much it would not fit on this paper!" Maggie (a Bristol primary school pupil).}

The workshops that can follow the assemblies take place in normal primary school classrooms that are converted into a 'laboratory' for the day. All chairs are removed and the tables put together into three large workstations and are covered with newspapers. Each table will have an investigation set up for pupils to explore in pairs and under the leadership and supervision of a trained postgraduate chemist. The investigations are designed to be complete in 30-40 minutes and are used to support measuring, investigatory and teamwork skills. The experiments include the iodine clock investigation where students determine how much water is needed to slow up the reaction until it changes at 60 seconds. A magnesium and hydrochloric acid experiment, where the time taken for the magnesium metal strip to completely react with the acid and disappear is recorded with different known concentrations of acid. These results are used to work out the concentration of an 'unknown' concentration of acid by comparison. The third experiment involves a slime (PVA and borax solutions) and thermoplastic investigation. Typically, the pupils move around to complete all 3 stations and without exception class teachers are amazed at what their pupils can do. Classes of up to 36 pupils can be accommodated in each of two sessions. All pupils and the adults present are given a safety briefing and are kitted out with appropriately sized lab coats, safety glasses and disposable nitrile gloves.

The value of such days to the schools is that they allow pupils to see and experience live science, to work with real scientists and to perform experiments using materials you cannot buy in a supermarket [10] and equipment that can be in short supply in some primaries. Being appropriately dressed not only meets health and safety requirements but also contributes to the impact of the workshops in the eyes of the pupils. The impact of the science day, or assembly, on the teachers, many of whom have no or little science training beyond 16 years of age themselves, can be viewed as 'continuous professional development (CPD) by diffusion'. The latter was investigated by a Bristol ChemLabS postgraduate student as the subject of her dissertation [11].

The value of the outreach is clearly not to be seen in terms of recruitment potential for undergraduates but as an opportunity for valuable soft skills development for the postgraduate chemists involved in these activities $[12,13]$. There are myriad advantages for students taking part in these activities. First, the student reengages with young learners and their teachers and is reminded of the excitement of science and the value that hands-on investigation has at that age. Second, for postgraduate students in particular, this can be a welcome break from research and for some an opportunity to see whether school teaching is for them as a career. Third, it allows these students to meet other students that they may not meet under every day circumstances. Although this seems quite tangential, for postgraduates working in a small group this is a most welcome way to become part of a bigger friendship group and from a research perspective we have seen many instances where postgraduate researchers from different groups are trying to solve similar problems and have been able to exchange ideas. For all students, being challenged by young learners and their teachers to explain why something has happened is important. In many cases it has challenged students to think more deeply about their science knowledge and there have been clear benefits to both undergraduate and postgraduate knowledge. As important is the honing of the skill of science communication, by interacting with these learners, the students are tested in terms of their ability to find ways to explain observations in language and using concepts that can be understood. Important skills such as time management, interacting with a range of learners (the enthusiast, the non-enthusiast, the timid, etc.) and their teachers and maintaining energy levels throughout the day are all most valuable skills that are also honed. All participants that take part have positives that they take away from each event.

The postgraduate students involved in all outreach from the School of Chemistry at the University of Bristol have to undertake training. The initial training takes place through the UK's National STEM Ambassador training provided by outside bodies. Then, for primary outreach, further training takes place in which the postgraduates go through the primary experiments with an experienced presenter. Further on the job' training takes place when a new postgraduate outreacher is taken with an experienced team as a supernumerary helper.

The activity is cost neutral for the departments because the 
consumables, administration, technical support, payment for those participating and transport costs are all paid for by the schools themselves or via sponsorship from professional bodies such as the Royal Society of Chemistry, via impact funding on research grants, monies set aside by the university for widening participation activity or from charities such as the Primary Science Teaching Trust (PSTT) [14]

The value of the primary outreach has been recognised overseas. Through training given by Bristol ChemLabS at both Rhodes University (Grahamstown) and the Sci-Bono Science Centre (Johannesburg) South Africa. At Rhodes University the same outreach activities are used both within the university's chemistry department for working with pupils from 'previously disadvantaged schools' and in township schools in the region, using postgraduate and honours chemists $[15,16]$. At the Sci-Bono Science Centre 'Gases in the Air' has been performed many times at the science centre's own lecture theatre and has been taken out to township schools. This talk is given in various South African languages/dialects by the centre's graduate science communicators. The primary outreach workshops have also been used with hundreds of French secondary school students, aged 14, hosted by French universities facilities over the last 5 years in the English language through the British Council (France) programme 'Science in Schools'. The Bristol component into this outreach project was mainly delivered with French speaking Bristol postgraduate chemists, to ensure that the safety elements were understood before continuing the workshops in English.' This allows students to hear and speak English in an authentic context while improving their image of science and researchers' [17]. Therefore, these activities and ethos seem to port to different countries and cultures without difficulty.

\section{3. 'Conveyer Belt' Outreach}

Part of the success with the primary schools outreach work is the consistency of the activities. This is, in part, due to the organisation of the practical equipment and the retention of the key people delivering. Multiple sets of the practical activities and lecture demonstration materials are revamped, repackaged and stored by a dedicated part-time outreach technician in a dedicated prep room. Multiple sets of 'spare; chemicals are also on standby to aid swift replenishment if needs be. Three primary outreach events can be, and have been delivered in three different venues on the same day. This does away with the need to waste time assembling outreach materials for one off events where equipment and chemicals has to be begged, borrowed or stolen from other areas to use with pupils. The two main outreach leaders have been in post for at least 8 years leading to a consistent approach that is sometimes missing on other outreach projects where staff turnover, or projects that are time limited, does not allow for the establishment of long-term relationships with schools.

\section{Additional Outreach Activities Provided for Primary Schools}

\subsection{Chem@rt}

This is a free to use activity that uses images taken from research or outreach within the School of Chemistry and makes available as stimulus material for the pupils to use as poetry and prose [18]. Teachers register that they are using the resource.

\subsection{Loan Boxes}

These are boxes of chemicals and equipment are available to local schools to help them deliver aspects of the science curriculum. These have been developed in conjunction with a team of local primary science coordinators at local primaries and funded by a grant from the PSTT. Schools collect the equipment and pay a small charge for the replacement of consumables.

\subsection{Undergraduate Ambassador Scheme}

Placement of students in local primary schools. Bristol ChemLabS continues to make use of the Undergraduate Ambassador Scheme (UAS) with chemistry students working in local primary schools as part of their final year projects work on aspects of the chemistry/science curriculum and its challenges [19]. These students work in a handful of primaries very close to the university and spend two to three days per week for two terms working with staff and pupils. This may involve group or whole class formal teaching and/or running practical work in science clubs.

\subsection{Visits to the School of Chemistry}

Visits to the teaching laboratories are made by primary pupils, but this is not common as most available lab space is taken up with outreach for senior secondary school students. The state schools that do visit the labs for the day on a regular basis come from north London and Devon, travelling for around 2 hours each way. The groups of 50 or so pupils, all Year 6, either undertake a circus of practical activities or come for a perfume making workshop day, Both activities involve tours of the School of Chemistry, lectures in the lecture theatre, a molecular model making session and lunch. Younger students are usually too small to stand at the undergraduate benches for any length of time so are discouraged from attending, Even so the department does have class sets of primary sized lab coats, very small safety glasses and even small and extra small nitrile rubber gloves for these visits. The north London school describes the visits as the best school trip the Year 6 pupils undertake in the whole year, 'including the residential camp!' 


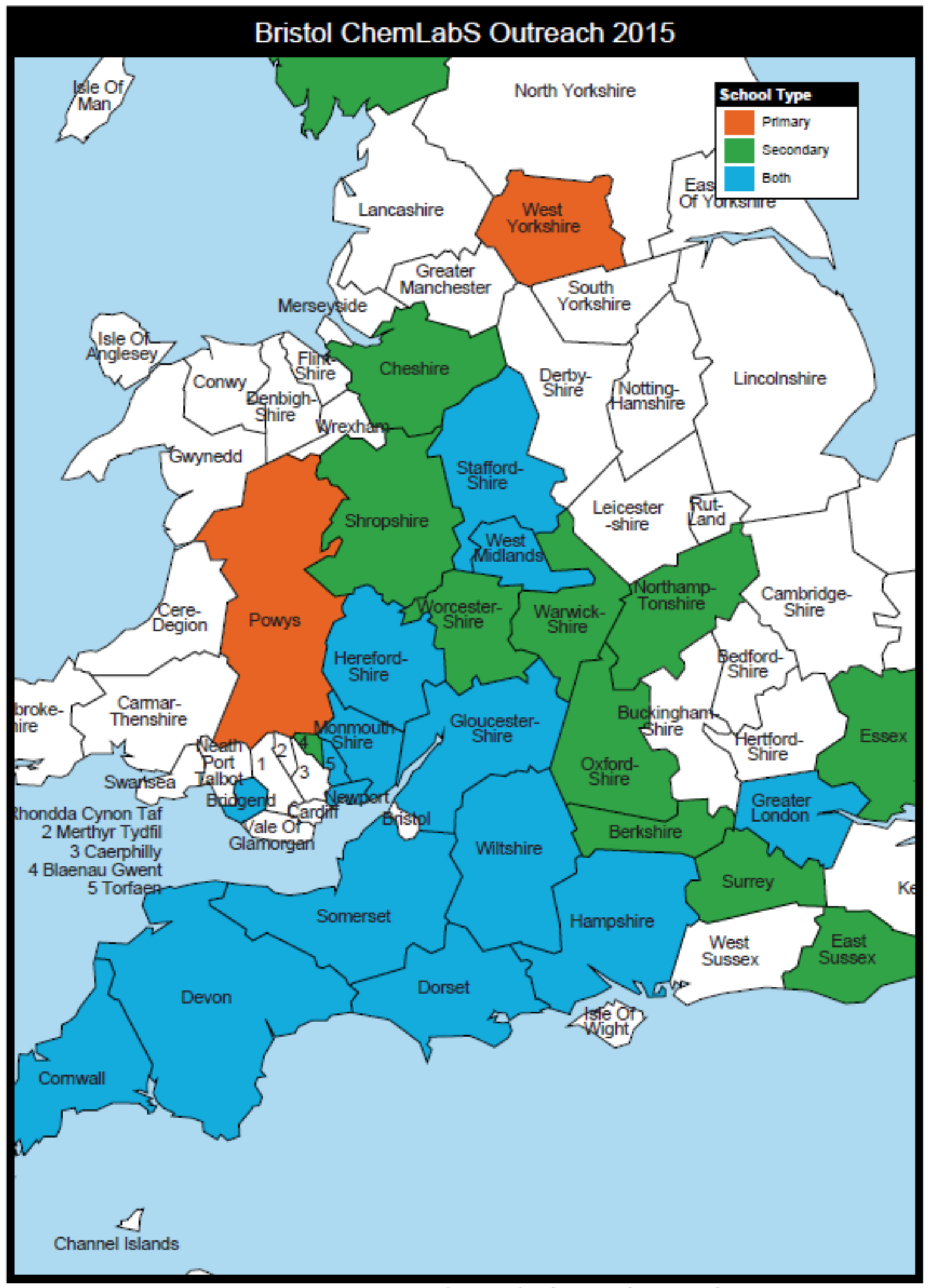

Figure 1. Counties in UK where engaged schools originate coded by school type: (brown) primary only, (green) secondary only and blue both primary and secondary engagements. 


\section{How has the Primary Outreach Developed over the Decade?}

In 2006, the first full year of primary outreach, when the organisation and content of workshops and of science assemblies were first devised, trialled and modified only 12 primary school events were made. These involved 2160 primary students, mainly in whole school assemblies of which 760 in Year 5 or 6 enjoyed one of 23 practical workshops. These mainly took place in Bristol, with only 2 other local counties visited. All of these events were free of charge to the schools.

During the academic year 2014/15, there were 66 events organised for 10,912 primary pupils and teachers from 170 identified schools during the year. These events were largely in the South of England and South Wales (Figure 1) and were mostly chemistry/science demonstration assemblies and three experiment chemistry workshops, with the vast majority being held within host schools. There was only one visit to the School of Chemistry made by primary schools in this year; a school from North London. A breakdown of engagements by year group is shown in Figure 2.

In the previous academic year, 2013/14, a record 76 primary school visits were made involving 13,063 primary pupils from the 176 schools taking part in some form of direct Bristol ChemLabS outreach. 2,039 teachers and teaching assistants in the 18 counties (plus a group from Malta) visited and saw the assemblies and benefited from 'CPD by diffusion' during these events. The counties visited can be seen in figure 2 and are mainly in the south of the England.

\section{Primary Outreach Breakdown}

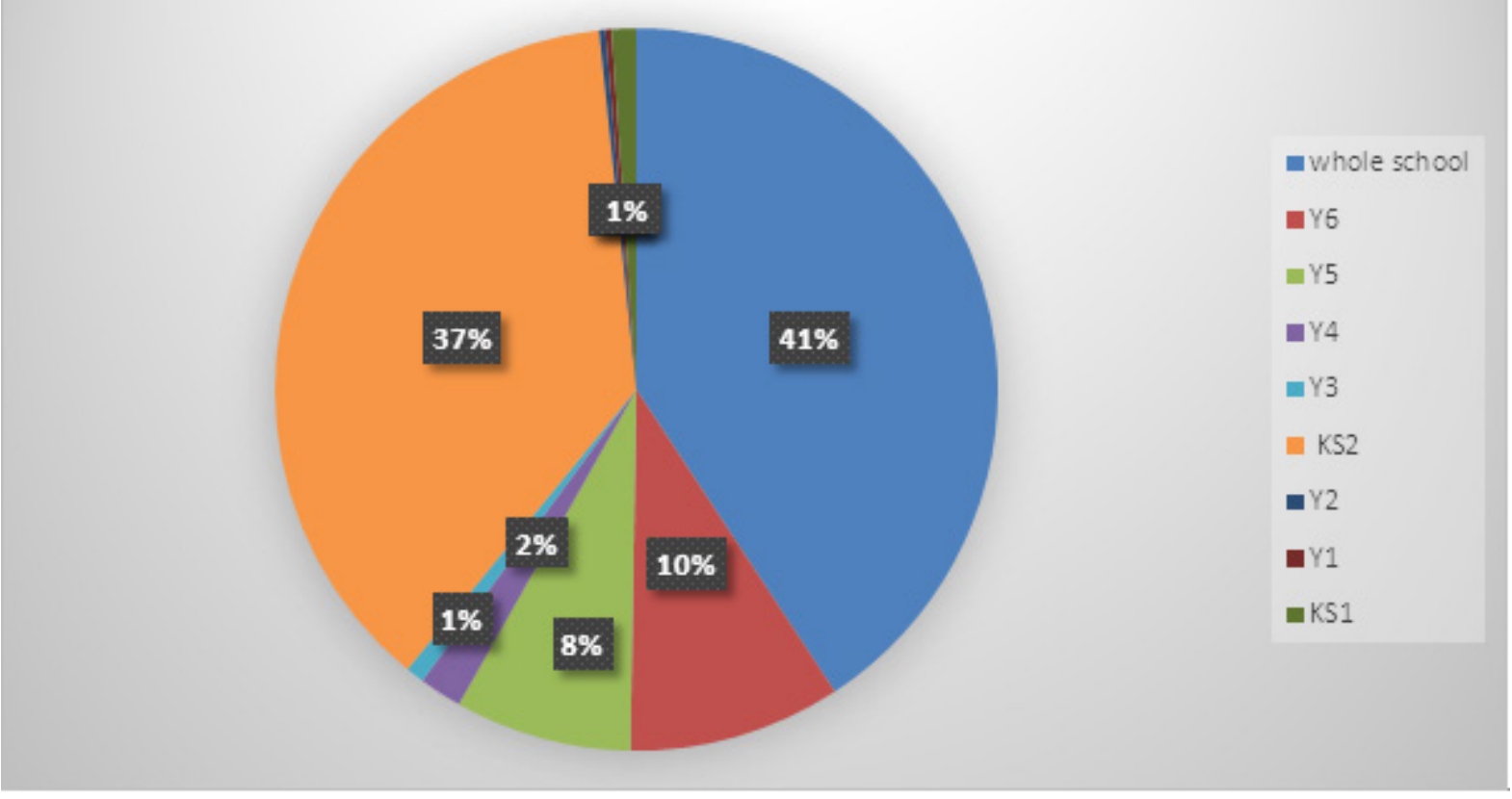

Figure 2. Primary school engagements in 2014/15 broken down by year groupings where known (KS1 is a composite of Years 1 and 2; KS2 is a composite of Years 3-6) 


\section{How Do We Know What We Are Doing is Any Good?}

The frequency of repeat bookings or contacts made from new schools whose teachers have transferred or become promoted to other schools is one measure of success. The inclusion of these engagements being written into the schools year calendar is another. Bristol ChemLabS no longer goes down the route of 'death by feedback questionnaire' as we did in the early days of the project. Initially we found we learnt more from impromptu verbal feedback from teachers than through sifting through hundreds of questionnaires filled in by pupils who would prefer not having the end of exiting activities dampened by paperwork they did not want to do. The preferred form of feedback has been via unsolicited emails from teachers, head teachers, school governors and even parents of children engaged as well as from thankyou letters from participating pupils.

From such feedback, and from direct word of mouth, we have learnt that the content and style of delivery of the assembly and for the workshops is exactly as expected. The comments made by a primary science coordinator from a 2016 visit to her school, are typical of comments received, although not usually touching on all areas at one time!

'The assembly and following workshops were fab! The children were excited and engaged and were talking about it using the correct scientific vocabulary all week. I heard so many conversations at playtimes and in the corridors about hydrogen exploding, never mind in lesson times! It was great to see all the children using chemicals and having experiences we might not be able to present them with in the usual realms of primary school. They loved wearing the lab coats and glasses and feeling like real scientists. I would definitely recommend a Chemlabs assembly and workshops to any school wanting to raise the profile of science or kick start a science week, as we did. It was a total hit with the children and staff were wowed too and ready to take the children forward with science learning for the rest of the week. A massive thank you to the Chemlabs team who worked with us! Thanks for a great WOW start to our science week!'

Another example of feedback from the 'Science Lead' at another primary school: "Thank you for coming into our school and inspiring and wowing our children with chemistry. The afternoon was well organised and age appropriate. Professor Tim had all of the children engaged and was able engage and involve all of our children from year 3 to year 6 . All staff have since commented on the excellent quality and engagement of all pupils during the demonstrations. The children were still talking about what they had experienced the following day and all demonstrated that they had increased knowledge of science as a result of the afternoon. Thank you again for coming into our school and I hope that we have to opportunity to have you back in school again in the near future."
More feedback can be seen among the reports of primary activity on the outreach website at http://www.chemlabs.bris.ac.uk/outreach/primary/Precent.h tml.

We have not received a letter of concern, complaint or criticism in 11 years. Another indicator of success is the 'good value for money' support proffered by professional bodies and charities in repeated sponsorship of these events. Part of the early recognition is demonstrated by its contribution to the 'Big Tick' Business in the Community Education Awards to Bristol ChemLabS in 2009, 2010 and 2011.

Building links with primary schools, their teachers and the pupils is important. It is known that interest in science can be turned off completely in these early years of learning $[20,21]$ and support for primary teachers to raise their own confidence is essential as is the realisation as to what their own pupils can do in science when they are provided with the opportunity and appropriate equipment.

\section{Conclusions}

The Bristol ChemLabS Outreach programme for primary schools is seen as a successful approach by a variety of actors ranging from the primary pupils and teachers, through the University of Bristol postgraduate chemists and professional organisations to overseas universities. With well organised chemistry activities that are age appropriate the project is always in demand. One measure of the perceived quality of the event is the number of repeated requests from paying schools with the longevity of the project being another.

\section{Acknowledgements}

This paper is an extension to work first presented at the 5th Eurovariety in Chemistry Education (2013 Conference) held at the University of Limerick, Ireland.

\section{REFERENCES}

[1] D.E. Shallcross, T.G. Harrison, T.M. Obey, S.J. Croker \& N. C. Norman, Outreach Within the Bristol ChemLabS CETL (Centre for Excellence in Teaching and Learning)', Higher Education Studies, CCSE, Vol.3, No.1, 39-49, 2013.

[2] T.G. Harrison and D.E. Shallcross, Towards Sustainable Public Engagement (Outreach), New Directions in the Teaching of Physical Sciences, Higher Education Academy UK Physical Sciences Centre, Issue 6, 41-46, 2010.

[3] D. E. Shallcross and T. G. Harrison, The Role of the School Teacher Fellow, Chemistry Education Research and Practice, Royal Society of Chemistry, Vol.8, No.1, 101-104, 2007.

[4] D.E. Shallcross and T.G. Harrison, The Impact of School 
Teacher Fellows on Teaching and Assessment at Tertiary Level, New Directions in the Teaching of Physical Sciences, Higher Education Academy UK Physical Sciences Centre, Issue 3, 77-78, 2007.

[5] T.G. Harrison and D.E. Shallcross, What should be Expected of Successful Engagement between Schools, Colleges and Universities?, School Science Review, Vol.91, 97-102, 2010.

[6] Online available: http://www.bbc.co.uk/news/education-2104 2923 (last accessed 23/12/15).

[7] Online available: http://www.chemlabs.bris.ac.uk/outreach/ (last accessed 23/12/15)

[8] D. E. Shallcross, T.G. Harrison, S. Wallington and H. Nicholson, University and Primary School Links, The Bristol ChemLabS Experience, Primary Science Review, Vol.94, 19-22, 2006.

[9] A. Griffin, T.G. Harrison, D.E. Shallcross, Primary Circuses of Experiments', Science in School, Vol. 7, 28-32, 2007.

[10] J. Tuah, T.G. Harrison and D.E. Shallcross, A Review of the Use of Demonstration Lectures in the Promotion of Positive Attitudes Towards, and the Learning of Science With Reference to 'A Pollutant's Tale', A Demonstration Lecture on Air Quality and Climate Change, Romanian Journal of Education, Vol.1, No. 3-4, 93-102, 2010.

[11] S.R. Glover, It Is Not Just About the Kids: The Effects of University-Led Outreach on Teachers and the Role of The School Teacher Fellow', PhD Thesis Submission, University of Bristol, 2016.

[12] T.G. Harrison, K.L. Hanford, B.T. Cheesman, G. Kaur, S.D. Franklin, A.M.C Laurain, M.I. Medley, A.C. Rivett, K.L. Shallcross, K.E. Shaw, S.J. Williams, D.E. Shallcross and L. Sellou, The many positive impacts of participating in outreach activities on postgraduate students, New Directions in the Teaching of Physical Sciences, Higher Education
Academy UK Physical Sciences Centre, Issue 7, 13-18, 2011.

[13] D. Overton and T. Overton, Primary discoveries, Education in Chemistry, Royal Society of Chemistry, November, Vol.52, No.6, 12-15 2015. Online available: http://www.rsc.org/eic/2 015/11/collaboration-chemistry-teaching-primary-school-out reach/ (last accessed 23/12/15).

[14] D.E. Shallcross, K.G. Schofield and S.D. Franklin, The Primary Science Teaching Trust and the Journal of Emergent Science', Journal of Emergent Science 9, 8-9, 2015.

[15] T.G. Harrison, D.E. Shallcross, N.C. Norman, J.D. Sewry and M.T. Davies-Coleman, Publicising Chemistry in a Multicultural Society Through Chemistry Outreach, South African Journal of Science, Vol.107, No.11/12, 2011.

[16] S.N. Sunassee, R.M. Young, J.D. Sewry, T.G. Harrison, D.E. Shallcross, Creating climate change awareness in South African schools through practical chemistry demonstrations, Acta Didactica Napocensia, Vol.5, No.4, 31-48, 2012.

[17] Online available:https://www.britishcouncil.fr/en/programme s/education/schools/science-schools, (last accessed 18 December 2015).

[18] A.C. Rivett, T.G. Harrison and D.E. Shallcross. The Art of Chemistry', Primary Science Review, Vol.110, 9-13, 2009.

[19] T.G. Harrison, D.M. Smith and Dudley Shallcross, Final Year School Projects: The Bristol ChemLabS Use of the Undergraduate Ambassador Scheme, Acta Didactica Napocensia, Vol.2, No.2, 35-40, 2009.

[20] C. Murphy, J. Beggs, I. Hickey, J. O'Meara, and J. Sweeney, National Curriculum: Compulsory School Science - Is It Improving Scientific Literacy?', Educational Research, Vol.43, No.2, 189-199 2001.

[21] T. Pell and T. Jarvis, Developing Attitude to Science Scales for Use With Children of Ages from Five to Eleven Years, International Journal of Science Education, 23, 847-862 (2001). 